\title{
Resistencia y reivindicaciones de las mujeres en las guerras de independencia de Colombia: una aproximación a través de sus cartas y reclamaciones
}

Resistance and demands of women in Colombia's wars of independence: an approach through their letters and claims

Academia Colombiana de Historia Roger Pita Pico

rogpitc@hotmail.com

Recibido el 4 de agosto de 2018

Aceptado el 27 de setiembre de 2019

[1134-6396(2019)26:0; 609-630]

http://dx.doi.org/10.30827/arenal.v26i2.7857

\section{1.-Introducción}

Desde sus inicios y por mucho tiempo, la historiografía colombiana se dedicó fundamentalmente a elaborar una historia política exaltando la vida de generales, nobles patricios y presidentes, en una concepción muy estrecha de la propia realidad. Era una versión protagónica que casi siempre hacía alusión al género masculino y a pequeños grupos dominantes pero dejaba por fuera a una multiplicidad de actores sociales que yacían prácticamente invisibles ya fuera en términos de clase, casta, edad, género u oficio ${ }^{1}$.

Ante estos vacíos, la corriente de la historia social y la de los grupos subalternos buscaron rescatar a aquellas personas del común que se encontraban bajo el control de grupos dominantes, dentro de lo cual emergieron varios estudios sobre las mujeres ${ }^{2}$.

1. GUHA, Ranajit: "Prefacio a los estudios subalternos". En: RODRÍGUEZ FREIRE, Raúl (comp.): Estudios Subalternos: una cartografia a (des)tiempo. Popayán, Editorial Universidad del Cauca, 2013, pp. 73-74.

2. Una constatación del auge de los estudios sobre la historia de las mujeres es el hecho de que en España entre 1976 y 2005 se registraron más de 600 tesis doctorales sobre esta temática. TORRES RAMÍREZ, Isabel de y TORRES SALINAS, Daniel: Tesis doctorales sobre estudios de las mujeres en las universidades de España (1976-2005). Análisis bibliométrico y repertorio biblio- 
Durante el periodo de dominio hispánico, en la Nueva Granada ${ }^{3}$ las mujeres vivieron sometidas y discriminadas bajo los rigores de una sociedad jerarquizada de carácter patriarcal que incorporaba elementos de la tradición judeo-cristiana y del derecho canónico ${ }^{4}$.

Mayor fue el papel asumido por las mujeres durante los movimientos revolucionarios acaecidos a principios del siglo XIX en los cuales los españoles y los criollos neogranadinos se trenzaron en una aguda lucha política y militar por el dominio de estos territorios americanos ${ }^{5}$. Sin embargo, la historiografía decimonónica se concentró en exaltar a las mujeres blancas y de la élite como participantes activas en este convulsionado periodo.

Especial atención merecieron aquellas esposas, amantes, hijas y madres de aquellos hombres que ostentaban el poder, como presidentes, oficiales de alta graduación y funcionarios de gobierno. Son igualmente abundantes las referencias documentales a los devaneos amorosos de los dirigentes republicanos Francisco de Paula Santander, Simón Bolívar, Antonio José de Sucre y José María Córdova ${ }^{6}$ en sus escritos y colofones de sus cartas, así como también las solicitudes de esposas de los altos mandos militares en demanda de medias pagas o pensiones de sus maridos, peticiones que por lo general gozaban de oportuna atención.

Entre tanto, aquellas mujeres anónimas y de extracción popular se las percibía despectivamente. En general, no se valoraba su rol en su verdadera dimensión sino en perspectiva del apoyo brindado a los hombres protagonistas de esas gestas ${ }^{7}$. La investigadora María Himelda Ramírez propuso hace unos años una relectura de la historia patria desde la perspectiva feminista, lo cual implica superar la invisibilidad de las mujeres y desmitificar el culto a heroínas como Antonia Santos o Policarpa Salavarrieta.

gráfico. Sevilla, Instituto Andaluz de la Mujer, 2007, 19. Sobre el papel de las mujeres en las guerras de Independencia en otras naciones hispanoamericanas, véase: GUZMÁN PÉREZ, Moisés (ed.): Mujeres y revolución en la independencia hispanoamericana. Morelia, Instituto de Investigaciones Históricas de la Universidad Michoacana de San Nicolás de Hidalgo, 2013; GARCÍA LÓPEZ, Ana Belén: "La participación de las mujeres en la independencia hispanoamericana a través de los medios de comunicación”. Historia y Comunicación Social, 16 (2011) 33-49.

3. Hoy república de Colombia.

4. VELÁSQUEZ TORO, Magdalena: "Condiciones jurídicas y sociales de la mujer". En: Nueva Historia de Colombia. Bogotá, Editorial Planeta, Vol. IV, 1998, p. 10.

5. Para el caso de España, véase FERNÁNDEZ GARCÍA, Elena: Mujeres en la guerra de la independencia. Madrid, Silex, 2010. En relación a Colombia vale mencionar el estudio clásico de: MONSALVE, José Dolores: Las mujeres en la Independencia. Bogotá, Academia Colombiana de Historia, 2010.

6. Véase por ejemplo: QUINTERO MONTIEL, Inés: "Bolívar: las mujeres, la política y la gloria". Revista Credencial Historia, 274 (2010) 2-6.

7. LUX MARTELO, Martha Elisa: "Las mujeres en la Independencia en la Nueva Granada: acciones y contribuciones". En: Historia que no cesa. La Independencia de Colombia, 1780-1830. Bogotá, Universidad del Rosario, 2010, p. 174. 
Aunque la historiografía colombiana no ha abordado todavía las múltiples facetas desarrolladas por las mujeres en el marco de estos años revolucionarios ${ }^{8}$, se sabe que tuvieron un papel activo en el fragor del combate, en las contribuciones económicas y en la provisión y alojamiento de las tropas. De igual manera, debieron afrontar grandes sacrificios con la pérdida de sus seres queridos, las persecuciones, la confiscación de bienes, los saqueos y los destierros.

En el marco del bicentenario de la Independencia de Colombia, el presente texto pretende mirar cómo las guerras de Independencia afectaron la vida de las mujeres, tanto en su entorno social y económico como en sus relaciones sentimentales, todo esto visto desde el prisma de las cartas firmadas por ellas mismas. Es decir, se busca sondear los alcances de la tensión política y militar desde la perspectiva de las mujeres, con todos sus temores, sus expectativas y sus esperanzas.

El estudio abarca las tres fases del periodo de Independencia: la Primera República Federativa que va desde 1810 hasta 1815, la Reconquista española que comprende los años entre 1815 y 1819 y la Segunda República que se inaugura con el triunfo crucial alcanzado por los patriotas en la batalla de Boyacá y que da lugar a la recuperación definitiva de todo el territorio.

La investigación se enfoca en las mujeres anónimas y en aquellas pertenecientes a los sectores populares que han sido invisibilizadas en la historia, lo cual implicó una exploración y un trabajo de exploración más minucioso en los archivos para detectar cartas escritas por ellas.

Antes que nada, vale aclarar que la información sobre estas mujeres es muy exigua tanto en el periodo de dominio hispánico como en la Independencia, lo cual tiene su explicación en el nivel de subordinación de este segmento social. Escasamente se hacían visibles en los expedientes de causas judiciales. El número de cartas firmadas por mujeres halladas en los archivos documentales no llega ni siquiera al 5\%. Es más, en muchas ocasiones, conocemos el sentir y las inquietudes de ellas por cuenta de las diligencias adelantadas por los gobernantes, los jueces o los defensores encargados de levantar testimonios y declaraciones a veces con cierta distorsión. Debe reconocerse además que la mayor parte de las cartas disponibles en los archivos documentales colombianos hace alusión al bando republicano y eso de alguna manera se vio reflejado en el número de casos aquí registrados.

El género epistolar adquirió especial auge en las últimas décadas como un importante filón historiográfico9 ${ }^{9}$ Para el caso específico de las mujeres como

8. RAMÍREZ, María Himelda: "Las mujeres en la Independencia de la Nueva Granada. Entre líneas". La Manzana de la Discordia 5-1 (2010) 47. Véase además: GONZÁLEZ ERASO, Judith Colombia: "Representaciones de las mujeres en la Independencia desde la historiografía colombiana". Historelo. Revista de Historia Regional y Local, 3-5 (2011) 169-190.

9. RODRÍGUEZ JIMÉNEZ, Pablo: Cartas de amor en tiempos de guerra. Bogotá, Universidad del Rosario, 2014, p. X; MESTRE SÁNCHEZ, Antonio: "La carta, fuente de conocimiento histórico". Revista de Historia Moderna, 18 (2000) 13-26. 
remitentes de cartas, vale precisar que no contaron con la misma posibilidad de acceder con tanta frecuencia a esta forma de comunicación. Desde tiempos del dominio hispánico, en ciertas circunstancias la legislación les había negado a ellas la posibilidad de dirigirse directamente ante las autoridades políticas y judiciales, pues estaba previsto que debían hacerlo a través de sus padres o esposos. A esto habría que sumarle la escasez de papel que se hacía más profunda por efectos de la guerra y, por otro lado, el grado de alfabetismo que proporcionalmente era más bajo en las mujeres ${ }^{10}$, prueba de lo cual fue el hecho de que algunas cartas eran escritas y firmadas por terceros. Casi nula es la inclusión de cartas escritas por mujeres dentro de los acervos epistolares publicados, alusivos al periodo de Independencia.

La muestra de 15 cartas aquí recopiladas forman parte de archivos históricos colombianos, principalmente el Archivo General de la Nación y a nivel regional el Archivo Central del Cauca. Se encuentran ubicados estos documentos al interior de fondos oficiales correspondientes al periodo de Independencia, en especial el fondo Secretaría de Guerra y Marina del Archivo General de la Nación. Este conjunto de cartas corresponden a reclamaciones o solicitudes de beneficios y concesiones dirigidas a autoridades políticas y militares tanto del orden provincial como del orden central, peticiones concretas que por lo general eran firmadas por las mismas peticionarias y que solo cumplían un trámite administrativo en busca de una pronta respuesta. Dentro de la muestra, únicamente dos de las cartas analizadas son de carácter privado, lo cual es un reflejo del escaso número de este tipo de escritos inmersos en un cúmulo de correspondencia oficial.

\section{2.-Intercesoras de sus seres amados}

Frente a las dificultades de sus seres amados, las mujeres supieron aprovechar los canales disponibles para interceder ante las autoridades en procura de concesiones o mejores condiciones para ellos. Para este propósito no vacilaron en desplegar todo su poder persuasivo y de poner de presente sus angustias y penurias con el objeto de obtener decisiones favorables para su círculo de allegados. No obstante, en algunos casos específicos, el general Bolívar se negó a atender este tipo de solicitudes tras reiterar que eran los militares directamente implicados los que debían elevar el reclamo.

10. El número total de escuelas públicas para niñas en Colombia durante los primeros años de vida republicana no llegaba ni siquiera a 20 en contraste con los más de 300 establecimientos para niños. PITA PICO, Roger: "De niñas escolares a madres y esposas: restricciones a la educación femenina en Colombia durante la temprana vida republicana, 1820-1828". Revista Interdisciplinaria de Estudios de Género, 3-5 (2017) 35. 
La cárcel fue quizás el castigo más frecuente aplicado en medio de la tensión y la persecución política vivida en las guerras de Independencia. Este tipo de condena motivó a no pocas mujeres a abogar por sus seres queridos.

Ese fue precisamente el clamor expresado a mediados de 1816 en Santa $\mathrm{Fe}^{11}$ por una mujer ante el comandante de Reconquista don Pablo Morillo para que su esposo fuera liberado de la prisión a que había sido confinado pocas semanas después de la retoma española de esta capital:

\section{Excelentísimo Señor:}

Doña Ignacia Morales, mujer y conjunta persona de don Gerónimo Mendoza, por quien presto voz y caución a causa de hallarse preso y sin comunicación en el Colegio del Rosario, ante V. E. con mi mayor veneración digo: que el citado mi marido desde el día en que se vino a mi casa a purificar una inquisición fue conducido a la cárcel como lo fue mi criada a la del divorcio. A ese tiempo, él se hallaba enfermo de los males habituales que padece. En la prisión se le han agravado y mi consternación se aumenta cada día, sin embargo de que vivo satisfecha de la buena conducta de mi marido antes de la revolución, y en todo el tiempo de ella, como es notorio a todo este público, de cuyos moradores puede V. E. informarse.

Yo, señor, me veo hoy en el mayor desamparo con cinco hijos pequeños. Con una madre que cuenta de edad cerca de ochenta años. Y tengo la honra de ser hija de un padre que con la más acendrada fidelidad sirvió al Rey Nuestro Señor la larga serie de más de sesenta años, y que el gobierno revolucionario le despojó de su empleo por haber insistido en que no obedecía sus órdenes si no se le manifestaban las de Su Majestad, de cuya verdad puede también V. E. informarse.

Reclamo yo este mérito y la clemencia a que parece acreedora mi actual suerte, para que V. E. como reverentemente se lo suplico, se digne impartirla hacia mi inocente marido hombre de bien conocido. Espero sentir los efectos de la piedad, que imploro, concediéndome V. E. que salga a mi casa bajo la fianza que daré si fuese necesario, y que sea juzgado en el Consejo de Purificación a donde antes de su prisión ya estaba presentado con los documentos comprobantes de su conducta, y en cuyo tribunal existen. Mediante lo expuesto con el pedimento más reverente.

A V. E. pido y suplico, que se digne atender mis ruegos y proveer según ellos de que recibiré merced y en lo necesario.

Ignacia Morales ${ }^{12}$.

El 25 de julio el comandante Morillo ordenó exámenes que dieron cuenta del complicado estado de salud de este hombre. Ignacia presentó a varios testigos que

11. Hoy Bogotá.

12. Archivo General de la Nación (AGN), Sección Archivo Anexo I, Fondo Historia, tomo 21, ff. 175r-176r. 
corroboraron su fidelidad política y finalmente él logró ser absuelto tras pagar la fianza.

En el caso que se reporta a continuación, es María Ignacia Vargas la mujer oriunda de la ciudad de Tunja que interviene a finales de 1820 en defensa de su consorte Domingo, quien se hallaba prestando servicios en parajes distantes. Esta lejanía de su compañero de vida le había acarreado innumerables penurias y por eso impetró clemencia ante el vicepresidente Santander.

\section{Excelentísimo Señor:}

Señor, por medio de este memorial ocurro a la superioridad de Vuestra Excelencia, llena de confianza en su paternal clemencia que ha de oír con la mayor compasión mis humildes súplicas que se dirigen a hacerle presente la orfandad y desamparo en que he quedado con mi crecida familia por la usencia de mi esposo Domingo María Castillo que se halla prisionero en la Guayana padeciendo indecibles trabajos; y yo con mi afligida familia destituida de todo humano consuelo, sin tener arbitrio para nuestra subsistencia y llenas de indigencias por carecer aún de lo muy necesario para mantenernos; pero confiada en el corazón generoso y compasivo de Vuestra Excelencia, me atrevo a suplicarle con mi mayor rendimiento que interponga su grande autoridad para con el Señor Excelentísimo Presidente a fin de que como un efecto de su grandeza le conceda a dicho mi esposo la libertad que desea y licencia para venir a unirse con su desconsolada familia cuya sombra con ansia lo deseamos para nuestro consuelo y subsistencia, y este bien espero conseguir por la protección y paternal clemencia de Vuestra Excelencia tan grande beneficio que Dios Nuestro Señor le premiará a Vuestra Excelencia y yo con mi destituida familia quedaremos en este eterno reconocimiento.

Nuestro Señor dilate y felicite la importante vida de Vuestra Excelencia por muchos años para consuelo de los afligidos. Tunja y diciembre 17 de 1820 .

Puesto a los pies de Vuestra Excelencia su rendida:

[firma] María Ignacia Vargas ${ }^{13}$.

Esta solicitud fue puesta a consideración del presidente Simón Bolívar de cuya decisión final no hay rastros.

Desde los tiempos del dominio hispánico, la legislación había previsto el servicio militar como uno de los tantos castigos dispuestos para quienes habían incurrido en algún delito. Esa norma siguió vigente en el periodo de Independencia y es en ese contexto en que se inscribe la siguiente súplica de la viuda bogotana María Josefa Chaves en defensa de su hijo quien había sido sentenciado por infringir una promesa matrimonial. Siendo condescendientes con su situación, su comandante abrió la posibilidad de que saliera de la prisión pero bajo una expresa condición.

13. AGN, Sección República, Fondo Secretaría de Guerra y Marina, tomo 325, f. 1.019r-v. 
Excelentísimo señor:

María Josefa Chaves, viuda vecina de Bogotá y residente en esta capital, ante V. E. como mejor corresponda y con el debido respeto parezco y digo: que un solo hijo que me quedó llamado Bernardo Ramírez que se hallaba de cabo de milicias del pueblo de Ubaté y porque no quiso casarse con una mujer viuda, procedió el juez político a remitirlo al cuartel del depósito de esta capital. No es un delito este, señor Excelentísimo, que preste mérito para que a mi indicado hijo se le haya destinado de soldado veterano. Esto mismo le hizo presente al señor comandante Flórez solicitando su licencia y dicho señor le mandó que pusiese dos hombres en su lugar, en efecto mi hijo dio primero uno, después dos desertores que cogió y los entregó y como hasta la fecha no se haya verificado la tal licencia, ocurro a la piedad y clemencia de V. E. suplicando que en méritos de lo expuesto y con consideración a mi viudez, se digne mandar se le franquee a mi relacionado hijo Bernardo Ramírez su absoluta licencia para que se restituya al lugar de su vecindario y a su misma clase en que estaba de cabo de milicias. Por cuanto implorando la protección y amparo de V. E. suplico rendidamente se digne mandar, según solicito.

María Josefa Chaves ${ }^{14}$.

En vista de que el militar cumplió con lo acordado, el secretario de Guerra Pedro Briceño finalmente le otorgó la licencia absoluta.

Silvestre Soberano fue encarcelado por los españoles en la ciudad de Pasto tras demostrarse su inclinación a la bandera republicana. El 14 de marzo de 1821 el presidente de Quito don Melchor de Aymerich le conmutó la pena capital por el servicio de las armas en Cuenca, en reconocimiento a los servicios prestados por su familia al sistema monárquico y como un gesto con el aliado "heroico" pueblo de Pasto. No obstante, después de esto, Soberano escapó y el 11 de julio se presentó en Popayán ante el general patriota Pedro León Torres, jefe del Ejército del Sur.

La siguiente fue la emotiva carta de una de sus hermanas en la que expresa su alegría por haberse salvado de ir al patíbulo y lo insta vehementemente a cesar sus aventuras y a reflexionar sobre la conveniencia de enarbolar las banderas del Rey:

Pasto, marzo 28 de 1821.

Hermanito mío de todo mi aprecio: las dos que te incluyo te hará ver el interés que he tomado ya sacarte del abismo en que tu destino te había precipitado: acabas de salir, mi querido hermano, del sepulcro, y este milagro debes creer que solo yo pude conseguirlo. No es menester que yo te suplique que en lo sucesivo procedas como Soberón; es decir con honor, y como hijo de unos padres tan ejemplares como los nuestros. La Providencia divina con la vara de la tribulación, por el espacio de siete años te ha dado lecciones terribles, y desventurado

14. AGN, Sección República, Fondo Secretaría de Guerra y Marina, tomo 330, f. 430r-v. 
de ti si no te aprovechas de ellas; lo cierto es que con este objeto te prolongue la vida, y toda tu familia a quien tus desgracias han cubierto de luto, espera que en correspondencia de los señalados servicios que te hemos dispensado, nos des en lo venidero días de alegría y motivos de regocijarnos que prolongues tu existencia.

Quisiera así yo como las hermanas y hermanos remitirte algún socorro pero, como no sabemos a punto fijo de tu paradero, esperamos tu contestación para hacerlo, verifícalo por mano de Pachito Bucheli. Dinos las sensaciones que ha experimentado tu corazón a vista de la gracia que has recibido pues nosotras saltamos de contentas sabiendo que se ha logrado y restituido a la vida un hermanito a quien reputábamos por perdido y encomendábamos a Dios como muerto.

Espero con ansias ver tus apreciables letras para aumentar con ellas el imponderable regocijo que tu libertad inspira al corazón de tu apasionada hermanita que te desea felicidad y besa tu mano.

Rosa Soberón.

P.D. Por este correo siguen para el comandante don Francisco González varias cartas por las que te recomiendan a ese señor sus amigos, y con particularidad el más íntimo de ellos, y que de consiguiente tiene sobre su corazón un influjo sobre todos, lo que te prevengo para mayor consuelo tuyo ${ }^{15}$.

\section{3.-Las mujeres al frente de sus hogares y penurias económicas}

Sin lugar a dudas, el lamento mayor de las mujeres en el marco de las guerras de Independencia fue su crítica situación económica. La guerra fue un factor que acentuó la desunión y la desprotección de las familias. Notable fue el fenómeno migratorio de que fueron víctimas miles de individuos quienes, intimidados por las fuerzas enemigas, preferían salir en búsqueda de refugio a otras zonas en donde se sentían más seguros. Estas huidas precipitadas significaban el desamparo para los miembros de familia que se quedaban en casa.

El otro factor a considerar fue la dinámica de reclutamiento, ya fuera este forzoso o voluntario ${ }^{16}$. Ser llamado a las armas implicaba muchas veces el tener que marchar hacia comarcas remotas abandonando súbitamente a sus parejas sentimentales y a sus hijos con la desesperanza de que seguramente no había campo a las licencias que solían concederse a los militares que ostentaban algún rango de poder. Si bien en muchas de las órdenes de alistamiento se solía eximir a los individuos casados y a los hijos de viudas, en realidad las crecientes necesidades de pie de fuerza obligaron a relegar este tipo de restricciones.

15. AGN, Sección República, Fondo Secretaría de Guerra y Marina, tomo 7, f. 793r

16. TOVAR PINZÓN, Hermes: "La lenta ruptura con el pasado colonial". En: Historia eco-

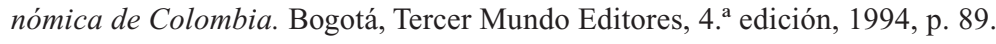


Algunas mujeres siguieron a sus parejas como parte integrante de las tropas, portando armas o disfrazándose de hombres pero casi siempre se dedicaban a tareas complementarias, ya fuera en la cocina, en el arreglo de los uniformes o en el cuidado de los heridos y de los enfermos.

No obstante, la gran mayoría debieron quedarse al frente de sus hogares ante la azarosa ida de sus compañeros a la guerra. Fueron ellas quienes debieron incrementar sus esfuerzos laborales o ingeniar actividades de supervivencia para suplir el vacío dejado por sus maridos.

Constante fue el rechazo de las familias y esposas al tener que separarse de sus hombres enrolados en el ejército. El vicepresidente Santander pudo palpar este inconformismo sin tener cómo hacerles comprender el sacrificio que todos debían hacer a favor de la naciente República: “[...] Vienen veinticinco reclutas y me rodean treinta mujeres, cuarenta niñitos llorando por sus maridos y padres; hablarles de patria es usar un lenguaje desconocido, despedirlas con imprecaciones es enviar a los pueblos treinta enemigos más; de halagos es perder el tiempo. Todo partido es terrible" ${ }^{17}$. Sin duda, era este un asunto delicado y de íntimas implicaciones que había que lidiar con bastante tino y cuidado.

Al sentirse indefensas y desprotegidas económicamente, las mujeres supieron aprovechar los canales existentes y acudieron ante los mandos políticos y militares proponiendo varias alternativas de alivio a su situación. En algunos casos se vieron en la necesidad de pedir "limosnas" o fue también intención de ellas procurar no verse afectadas por las órdenes de embargo. Otro tipo de representaciones tenía que ver con la posibilidad de acceder a los beneficios económicos derivados de la participación de sus esposos e hijos en la guerra: la exigencia ya sea de parte del prest ${ }^{18} \mathrm{o}$ de la pensión por muerte de sus seres amados o, en otros casos, lograr la autorización para que fueran licenciados del servicio o trasladados para que pudieran ayudar de cerca al sostenimiento económico. Pero, sobre todo, en ellas quedaba muy en claro el compromiso de mantener activa la solidaridad familiar en estas difíciles coyunturas.

Haber entregado sus tres hijos al servicio de la República y haber padecido persecuciones de los españoles fueron las razones que una cartagenera arguyó ante el general Bolívar para ser favorecida con un auxilio que mitigara su maltrecha economía doméstica:

17. CORTÁZAR, Roberto (comp.): Cartas y Mensajes del General Francisco de Paula Santander. Bogotá, Academia Colombiana de Historia, 1956, Vol. 2, pp. 301-302.

18. Sueldo o pago a los militares. 
Excelentísimo Señor Presidente:

Petrona Landete, vecina de Cartagena, y ante la superioridad de V. E. con la mayor veneración y respeto, parezco y digo: que la firmeza de mi opinión a pesar de lo débil del bello sexo me ha mantenido en suma miseria desde que los tiranos españoles tomaron la plaza de Cartagena de donde no pude emigrar por mis ningunos recursos, habiéndolo solo verificado uno de mis hijos, el cual fue prisionero en la provincia de Veraguas y remitido a la dicha ciudad de Cartagena donde a fuerzas de empeños y observando una falsa política, logré el sacarlo de las prisiones junto con otro hijo que tenía en el presidio por cuyo motivo no me fue posible el separarme de aquellos pérfidos enemigos pero logré el hacerlo el año [18]17 a sus fines llevándome en mi campaña todos mis hijos y avecindándome en el sitio de Arjona donde resido hasta el presente pasando mil miserias con el mayor gusto por hallarme separada de nuestros enemigos, y hallándome libre de los tiranos y en el sabio gobierno que premia las virtudes y firmeza de las opiniones, y teniendo mis tres hijos empleados en el servicio de la República, el uno en el ejército bloqueador de Cartagena y los dos en la ciudad de Mompox, y yo con dos hijas de estado honesto pasando las mayores miserias y trabajos como de todo puede V. E. verlo por el informe del señor corregidor del partido y aún del señor general ciudadano Mariano Montilla que puede estar informado de nuestra situación y opinión, suplico se sirva señalarme una pensión con que pueda remediar en parte mis escaseces, y la de mis dos hijas, haciéndolo en obsequio de nuestra libertad y la de su generoso corazón de cuyo favor recibiré gracia y merced.

Arjona, a septiembre 27 de 1820 .

Petrona Landete ${ }^{19}$.

Por los lados del interior, una mujer viuda y de avanzada edad residente en Guatavita elevó su ruego ante la comandancia militar para el regreso de su hijo enrolado en las huestes republicanas, quien era prácticamente su único sustento.

\section{Señor Comandante:}

María Josefa Rodríguez, vecina del pueblo de Guatavita y residente en esta ciudad, ante $\mathrm{V}$. con el debido respeto digo: que por el mes de noviembre del presente año fue reclutado en el escuadrón de Guías uno de mis dos hijos el mayor Domingo Ramos, que continúa en el servicio de las armas de la República, y yo con el mayor gusto de que se halle en este ejercicio pero como solo me quedaba otro de edad de doce años poco más o menos, nombrado José, el cual con su trabajo personal alimentaba mi vejez, por no tener otros auxilios de donde poderlo verificar; me vi de un momento a otro privada del que me suministraba, por haberlo cogido el día diez y seis del que rige en el pueblo de Guasca, con el

19. AGN, Sección República, Fondo Secretaría de Guerra y Marina, tomo 3, f. 291r. 
mismo objeto que el anterior; ignorando ser hijo de viuda como lo soy de José Ramos de oficio labrador del pueblo citado de Guatavita; en cuya virtud suplico a V. se sirva por un efecto de su bondad y justificación, mandar se le expida su licencia absoluta para que pueda subvenir al cuido de esta su afligida madre. Por lo que a V. pido y suplico se sirva proveer y mandar como solicito.

A ruego de María Josefa Rodríguez

Anselmo Portocarrero ${ }^{20}$.

El 27 de diciembre de 1819 se envió esta petición al gobierno provincial para decidir sobre este particular.

La crisis económica derivada del frenesí de la guerra afligió al conjunto de la sociedad pero que probablemente pudo ser más notoria en la comunidad esclava ${ }^{21}$ en razón a su postrera posición en la escala social. Era una época generalizada de escasez que significó para ellos intensos sacrificios y esfuerzos laborales de supervivencia. Los esclavos no fueron exentos de los procesos de incorporación militar, una situación que generó impacto económico en la supervivencia de sus esposas y de su prole.

Tras haber obtenido la negra Tomasa Cobo su libertad, le preocupaba sobremanera el hecho de que su consorte permaneciera aún en estado de esclavitud y expuesto a incontables peligros luego de haber sido enrolado en enero de 1822 en Popayán en el ejército republicano. Este es un fragmento de la sentida petición elevada al presidente Simón Bolívar para que tuviese especial consideración con los hombres comprometidos en matrimonio:

[...] yo fui esclava del Sr. Ramón Cobo y a fuerza de mi industria conseguí mi libertad pero sin que esta pudiese lisonjearme enteramente por haber dejado bajo el yugo de la servidumbre a mi esposo Gabriel. Este ha sido ahora entregado por su señora Tomasa Ortiz para soldado quizá por algún resentimiento debido a mi libertad; y como sé que V. E., en su sabio y político decreto ha eximido a los casados, por este motivo y por la notable falta que hace a su mujer y a sus hijos, a V. E. pido y suplico se sirva mandar se le licencie y se reemplace por uno de los solteros de la dicha señora ${ }^{22}$.

El déficit fiscal fue prácticamente una constante durante el proceso de Independencia. Ingentes fueron los esfuerzos de las autoridades políticas y de los coman-

20. AGN, Sección República, Fondo Secretaría de Guerra y Marina, tomo 1, f. 243r.

21. En 1810 el número de esclavos representaba apenas un 5\% del total de la población. RESTREPO, José Manuel: Historia de la Revolución de la República de Colombia en la América Meridional. Medellín, Universidad de Antioquia-Universidad Nacional, 2009, 5. ${ }^{\text {a }}$ ed., Vol. I, p. 14.

22. Archivo Central del Cauca (ACC), Sala Independencia, Civil II-6 Gobierno, signatura 6869 , f. 3 r. 
dantes militares por conseguir recursos para pagarle cumplidamente a la tropa ${ }^{23}$. El mismo gobierno nacional en su decreto del 4 de agosto de 1820 advirtió sobre las dificultades para hacer los pagos oportunamente y en efectivo ${ }^{24}$. Numerosas eran las penalidades y los peligros que debían afrontar los militares sin que estos sacrificios fueran debidamente compensados con un buen pago, situación que se agravaba ante el estado de orfandad en que quedabas sus familias.

Precisamente en reconocimiento de esta situación, la legislación republicana contempló la posibilidad de que, con autorización previa del militar, pudiese traspasarles a algunos de sus deudos parte de la paga. No obstante, la falta de recursos disponibles y las trabas operativas causaron también incumplimientos en la aplicación de esta medida.

Muy contrariada se sentía en 1820 la señora María Josefa Amaya al verse abandonada de su esposo reclutado, poniendo como denuncia la falta de regularidad en los pagos y los exiguos dineros transferidos que resultaban insuficientes para mitigar las cargas asumidas por ella al frente de su hogar.

Excelentísimo Señor Presidente:

Josefa Amaya, ante V. Excelencia, con el debido respeto, parezco y digo que hallándome sumamente destituida y en suma pobreza y sin amparo alguno en lo humano, desamparada de mi marido pues este me abandonó desde la Patria pasada por vivir a su gusto y sin votarme un pan a mí ni a su hijo, y teniendo mi hijo menor sirviendo en el cuartel de Artillería y sin tener mayor utilidad de él, pues el sueldo que le dan es muy poco y en malísima moneda, y a más de esto el día que le quieren dar le dan y el día que no, no le dan nada, y a más el muchacho es inútil para el servicio del ejército, pues así me lo han dicho los jefes de Artillería, y que me presenté a V. Excelencia para que se le dé su licencia, y en virtud de esto y de mi súplica y al mismo tiempo interponiendo el indulto publicado el día 20 de este y a más pidiéndolo por merced y gracia del buen suceso de nuestras armas, suplico a V. Excelencia se digne concederme lo que pido en caridad.

María Josefa Amaya ${ }^{25}$.

En respuesta emitida el 28 de julio, el comandante militar de Bogotá no autorizó la licencia del joven reclutado y, por otro lado, desmintió las acusaciones sobre incumplimiento en los pagos.

Reiteradas fueron las solicitudes de las viudas que, además de tener que sobrellevar el dolor por la pérdida de sus maridos, tenían que mirar cómo mantenían sus hogares. Precisamente en reconocimiento a las viudas y huérfanos, el gobierno

23. BUSHNELL, David: El Régimen de Santander en la Gran Colombia. Bogotá, El Áncora Editores, 1985, p. 224.

24. Decreto sobre asignaciones de sueldo a los servidores de la Patria. Bogotá, Imprenta Nacional, 1905, pp. 1-3.

25. AGN, Sección República, Fondo Secretaría de Guerra y Marina, tomo 6, f. 948r. 
republicano expidió la ley del 13 de octubre de 1821 mediante la cual les brindaba la posibilidad a estos afectados de acceder al montepío militar o ministerial siempre y cuando hubiese disponibilidad de fondos. La idea era que, a medida que mermaran los gastos militares, habría mayores posibilidades de conceder indemnizaciones a aquellos que no tuviesen derecho a pensión ${ }^{26}$.

Una dama oriunda de Mompox recurrió a gestionar el trámite de la pensión de su finado esposo como alternativa de salvación económica:

\section{Excelentísimo Señor:}

Inés Fernández Silguero, viuda del jefe del batallón que fue de la primera República Juan José León Vigil, ante V. E. con todo su debido acatamiento expone: que habiendo servido su consorte desde el momento que se oyó en la América la voz de la libertad y de la Independencia, tuvo el honor de dedicarlos en la carrera de las armas, en cuyo servicio tuvo más parte en la restauración de la villa de Tenerife, provincia de Santa Marta, en las expediciones a Guamal, Banco, Chiriguaná y demás inmediatos lugares, en la marcha con S. E. el Libertador hasta la rendición de Cúcuta y otras distintas comisiones que desempeñó con tanta más exactitud y decisión por la causa, con conocimientos que podría desempeñarlos un soldado que apenas comenzaba la gloriosa empresa de nuestra causa, le arrastraron a anteponer su vida por ella a sus intereses personales, obligaciones y otras particulares; sacrificándose gustoso por el bien general de la República. Así gloriosamente lo consiguió y así terminó infelizmente en el lamentable estado de una ausencia a que lo redujo la emigración del año de [18]15 en país extraño, donde nada le gravitaría sobre su alma más que la separación y abandono con que veía que dejaba a su consorte y una criatura fruto de nuestro matrimonio. Sí Excelentísimo Señor, tal y como va significado, me veo obligada por mis escaseces a manifestarlos a la piedad de V. E. Básteme señor ésta para que me permita $V$. E. le dirija mis súplicas y que penetrado altamente de mi situación se digne también concederme la gracia de declararme acreedora del montepío ${ }^{27}$ que me corresponde como tal viuda de uno de los jefes de la República, único apoyo con que cuento para el fomento y educación de aquella desgraciada joven y mi subsistencia a virtud del desamparo a que me ha sucumbido la suerte en su temprana muerte [...]. Por todo lo expuesto, y por la soberana autoridad que está refundida en $V$. E. y que tan dignamente desempeña espero la gracia que imploro y en justicia merezca de la bondad de V. E.

Mompox, 31 de agosto de 1821.

Inés Fernández Silguero ${ }^{28}$.

26. Recopilación de Leyes de la Nueva Granada. Bogotá, Imprenta de Zoilo Salazar, 1845, Vol. I, p. 23.

27. A la muerte del reclutado, el montepío militar era una fórmula de carácter mutual que permitió el pago de una asignación mensual para su pareja y sus hijos.

28. AGN, Sección República, Fondo Secretaría de Guerra y Marina, tomo 7, ff. 58r-59r. 
En el marco de las guerras de Independencia, el embargo fue utilizado como instrumento de represión para vulnerar las potencialidades del enemigo afectando no solo a los más acaudalados sino también a pequeños propietarios, modestos comerciantes e incluso a personas con exiguo patrimonio ${ }^{29}$. Uno de los tres órganos de represión creados por el gobierno de Reconquista fue la tan renombrada Junta de Secuestros, destinada a desarticular futuros esfuerzos económicos en favor de la gesta libertaria y a dejar en la orfandad y miseria a las familias de los "conspiradores" que atentaban contra el régimen español.

De manera directa o indirecta, este tipo de diligencias fiscales terminaba perjudicando a las esposas de los "desafectos" perseguidos. Una mulata liberta de la ciudad de Cartagena debió acudir a comienzos de 1816 ante las autoridades españolas solicitando que la orden de embargo dirigida contra su hijo no afectara las cortas pertenencias que con mucho sacrificio había atesorado.

Excelentísimo Señor:

Celedonia González, viuda vecina de esta ciudad, ante V. E. con el más profundo respeto parezco y digo: que don Miguel Andrés, sargento mayor del regimiento de Húsares, comisionado según comprendo para el embargo de bienes de los emigrados, ha tratado de hacerlo de los míos persuadido tal vez que pertenecen a un joven mi hijo legítimo llamado Cipriano Begambre que tuvo la desgracia por su poca o ninguna experiencia de haber servido en clase de oficial al gobierno revolucionario e insurgente, y por ello antes de la entrada de las tropas de nuestro amado Soberano el Señor Don Fernando Séptimo que Dios guarde, emigró con otros de su clase.

Es público y notorio en la ciudad que yo desde mi niñez he sido inclinada al trabajo y que con él haciendo biscochos, dulces y otras cosas he ganado muchos pesos, también lo es que cuando contraje matrimonio con Pedro Begambre, padre que fue de mi desgraciado hijo, introduje a él por título de dote cierta cantidad de alguna consideración que me fue donada por una señora de la ciudad nombrada doña Ana González, en cuyo dominio nací y me crie, con la cual y la ayuda de mi trabajo, estableció mi esposo una tienda de confitería, en cuyo manejo por algunos infortunios quebró y formando concurso de acreedores a sus bienes alegando yo los privilegios que franqueaba mi carta dotal, se me declaró la preferencia en los bienes embargados a mi esposo y se me entregó su importe en dinero y en efectos, con lo que continué trabajando de mi propia cuenta en la referida tienda [...].

Todo lo relacionado juzgo deberá resultar comprobado de las diligencias practicadas por el oficial comisionado, pero no obstante parece intenta continuar en mi perjuicio adelantando el embargo, y esto me obliga a ocurrir como lo hago a suplicar al benigno corazón de V. E. se sirva mandar que suspendiéndose aquella

29. TOVAR PINZÓN, Hermes: "Guerras de opinión y represión en Colombia durante la Independencia (1810-1820)”. Anuario Colombiano de Historia Social y de la Cultura, 11 (1983) 220-221. 
actuación se me de vista de lo obrado para justificar más en forma mis derechos, que en ello recibiré merced con justicia.

A V. E. suplico se sirva proveer como concluyo y en lo necesario juro.

Celedonia González ${ }^{30}$.

En respuesta emitida por el gobernador de Cartagena se dio vía libre a la pretensión de Celedonia y, por consiguiente, mandó deducir de los bienes incautados lo que justamente le correspondía.

En los albores de la Segunda República, el gobierno dispuso un alivio al ordenar que, aquellas mujeres que podían regresar luego de haber padecido largas migraciones, pudieran reclamar sus propiedades confiscadas ${ }^{31}$.

\section{4.-Clamor por los heridos de guerra}

La falta generalizada de recursos en los bandos patriota y realista alcanzó a tener impacto en el servicio de salud brindado a los combatientes afectados por enfermedades o por heridas sufridas en el campo de batalla. Es por esto que la escasez de medicamentos, las dificultades para pagar a médicos y cirujanos, además del estado deficiente de los hospitales militares, fueron circunstancias que se vieron reflejadas en los precarios niveles de atención a las tropas en combate ${ }^{32}$. A esto habría que agregarle otro factor agravante que era la omisión o negligencia de las autoridades o de las instancias encargadas de proveer servicio curativo a las huestes en campaña ${ }^{33}$.

Bajo este desolador panorama, no era extraño ver que las esposas y madres acudieran en procura de mirar cómo mitigaban las dolencias de sus seres queridos tras los estragos de la guerra y la precaria atención institucional. Cuando los reclutados resultaban incapacitados, doble era el trabajo de ellas puesto que, además de cuidarlos, debían mantener a flote la economía de sus núcleos familiares. A finales de 1819 una ciudadana santafereña pidió que su marido fuera licenciado del servicio por su estado crítico de enfermedad:

30. AGN, Sección Archivo Anexo, Fondo Embargos, tomo 2, f. 35r-v.

31. BERMÚDEZ, Suzy: "El "bello sexo" y la familia durante el siglo XIX en Colombia". Historia Crítica, 8 (1993) 38.

32. MARTÍNEZ MARTIN, Abel Fernando y OTÁLORA CASCANTE, Andrés Ricardo: "De Boyacá en los campos. La vida cotidiana a través de las condiciones de salud en los ejércitos del Rey y Libertador de Nueva Granada en 1819”. En: GUERRERO BARÓN, Javier y WIESNER, Luis (comp.): Memoria, Historia y Nación. A propósito del Bicentenario de la Independencia Latinoamericana. Bogotá, Universidad Pedagógica y Tecnológica de Colombia-Editorial La Carreta, 2010, pp. 243-275.

33. BUSHNELL, David: El régimen de Santander, p. 302. 


\section{Excelentísimo Señor:}

María Luisa Gallardo, vecina de esta ciudad, pobre de toda solemnidad y mujer legítima del cabo 2. ${ }^{\circ}$ de la 1. ${ }^{a}$ compañía del cuerpo de Artilleros José María Molano, ante Vuestra Excelencia con mi acostumbrado respeto digo: que hallándose mi marido muy enfermo, acometido de ictericia, de una avanzada edad y cargado de pueril familia, ya no es capaz de continuar en el servicio de las armas, aunque nuestros deseos son de servir del modo posible y contribuir a la defensa común de nuestra amada Patria. Por ello vengo en suplicar a la benignidad de Vuestra Excelencia se sirva expedirle su licencia absoluta, previo el reconocimiento de un facultativo respecto a su imposibilidad para el servicio, si Vuestra Excelencia lo estimare por conveniente o como mejor sea de su superior agrado, que en todo recibiré merced con justicia que imploro.

Santa Fe, octubre 29 de 1819.

María Luisa Gallardo ${ }^{34}$.

La autoridad militar ordenó enviar a José María a un médico quien pudo certificar que era inútil para seguir en el ejército republicano.

Ese mismo año desde la ciudad de Cartago en la provincia del Cauca, otra mujer redacta una carta implorando que su hijo enfermo fuera eximido del servicio, todo con miras a aliviar su maltrecha economía:

\section{Excelentísimo Señor:}

María Francisca de Ayora, vecina de esta ciudad, ante V. E. con mi acostumbrado respeto represento: que hallándome reducida cuasi al estado de mendicidad, y llena de unos males incurables, el menor haber perdido absolutamente la vista; y no teniendo otro apoyo en mi situación deplorable para mi subsistencia que un hijo solo (llamado Fulgencio del Castillo) el cual hace actual dos años que está en el servicio de la República en clase de sargento $1 .^{\circ}$ quien por su adhesión a la causa de la libertad, como también por las órdenes terminantes que ha expedido S. E. en esta provincia para que todo hombre haya de tomar las armas, prefirió voluntariamente seguir la carrera, dejándome sola y desamparada y sin el menor recurso que pueda valerme en medio de mi orfandad y miseria suma en que me veo. Estos males incalculables solo podrán remediarse implorando yo el auxilio de V. E. que no dudo hallar la protección que rendidamente solicito, franqueándosemele una licencia absoluta a dicho mi hijo, quien se halla actual en el hospital de Cali gravemente enfermo de varios accidentes que continuamente padece, los cuales le impiden las fatigas del servicio, pues ni este obstáculo previó, ni le contuvo para presentarse, conociendo prácticamente que jamás podría ser útil.

Por tanto, ruego a V. E. se sirva acceder a mi solicitud.

Cartago, mayo 19 de 1821.

María Francisca de Ayora ${ }^{35}$.

34. AGN, Sección República, Fondo Secretaría de Guerra y Marina, tomo 1, f. 193r.

35. AGN, Sección República, Fondo Secretaría de Guerra y Marina, tomo 6, f. 923r. 
Esta petición se envió al jefe del Ejército del Sur para que emitiera su dictamen. A varias leguas de allí, en la región central, una desesperada madre escribió en 1821 al presidente Simón Bolívar solicitando licencia temporal para su hijo reclutado en la lejana frontera con Venezuela. El propósito era transportarlo hasta su casa y brindarle allí todos los cuidados para garantizar su recuperación con el compromiso de que inmediatamente después se reincorporaría a su batallón.

Excelentísimo Señor Libertador:

María Antonia Santos, vecina de la ciudad de Tunja y residente en la villa de Soatá, con el respeto que acostumbra se postra a sus pies de S. E. y dice: que hace el espacio de seis a siete meses se halla su hijo José Vicente Gómez (teniente del Batallón Tiradores) enfermo en la villa de San José de Cúcuta, inficionado de Gálico y coto, y pretendiendo como madre asistirlo y medicinarlo para su consuelo, el bien de él y el de la República, y no hallando otro medio más eficaz que el de acogerse del paternal y piadoso corazón de V. E. que está abierto para amparar y consolar a las viudas que se postran a sus pies y le comunican sus flaquezas, pues es quien les da el remedio como Padre de la República; satisfecha del benigno y caritativo corazón de S. E. que atiende y no despecha a ninguna persona sin que le conceda la merced que le pido. En esta virtud suplica a V. E. se digne en caridad mandar se le franquee licencia temporal inter se cura de las enfermedades que padece y con este permiso se transporte a esta villa en donde podré con más actividad asistirlo y medicinarlo, llevándolo a temperamentos que hay inmediatos a esta, que son destructivos a la enfermedad que este oficial padece. Esta es la gracia y merced que pide en caridad.

Puesta a los pies de S. E. su más humilde servidor que besa las manos de su persona.

María Antonia Santos ${ }^{36}$.

Bolívar dispuso que, si no había cómo sanarlo en el hospital militar, el comandante del cuartel general debía otorgarle el respectivo permiso, tal como efectivamente se formalizó en San José de Cúcuta el 15 de marzo.

\section{5.-Del amor terrenal al amor eterno}

De todo el acervo epistolar que reposa en los archivos, las cartas de amor de los sectores populares son sin duda las más escasas. El carácter iletrado de la mayoría de los militares rasos pudo hacer más difícil la comunicación que, en vista de las circunstancias, se reducía prácticamente a los mensajes verbales transmitidos

36. AGN, Sección República, Fondo Secretaría de Guerra y Marina, tomo 7, f. 292r. 
con no pocas peripecias y debiéndose franquear caminos a través de una compleja geografía de profundos contrastes.

Una de esas pocas cartas que sobrevivió en el tiempo fue aquella que María Celestina Rubio envió a principios de 1811 desde Santa Fe a su esposo el soldado Manuel Cárdenas, quien se vio inmerso en medio de dos tensiones políticas, por una parte, la confrontación interna entre centralistas y federalistas y, por la otra, la lucha militar para expulsar a los españoles de las provincias del Sur.

En este corto escrito se plasma de manera explícita el amor filial y el sentimiento por la ausencia del ser querido. Se advierten allí también las dificultades económicas que debía afrontar la esposa y la solidaridad familiar como paliativo. De igual modo está presente el fervor religioso y las plegarias divinas en aras de salvaguardar al ser amado en la guerra.

Santa Fe, 19 de febrero de 1811.

Señor don Manuel Cárdenas: mi muy amado y querido esposo de mi mayor estimación. Me alegraré que al recibo de esta se halle con muy cabal salud como mi fino amor le desea. Muy señor mío: yo y todos sus hijitos quedamos buenos a Dios gracias, siempre a su disposición y pensándolo mucho que si V. md. nos piensa allá, más lo pensamos por acá pues ya no vemos la hora de verlo y me parece que no le he de volver a ver por lo que $\mathrm{V}$. Md. me dice que viva muy honrada no tenga que pensar en eso pues yo buen cuidado lo tengo como lo verá cuando venga. Por lo que son los niños, ellos están con mucho cuidado, solo a Manuel lo quité de la escuela de donde estaba y lo pasé a Santo Domingo porque ya no tenía con qué pagarle al maestro en donde estaba y allá no me llevan nada y que puede aprender algo más. El encargo que le hago es que tenga muy presente a Nuestra Señora de Chiquinquirá y a mi Señora Santa Librada para que lo saquen con bien y lo tengan con salud pues yo le tengo hecha promesa el irla a ver por la pascua y en estos días recoger la plata aunque sea de limosna porque lo saque y lo traiga presto y con salud; su madre y todos mis hermanos lo saludan mucho, que están pensando mucho y deseando verlo. Mi hermano Pedro y mi hermana Felipa lo saludan muy de corazón, mi mamá Josefa y mi hermana Ignacia también lo saludan mucho, su compadre Ramón y su comadre Ignacia lo saludan infinito que ellos mismos quisieran ser los portadores para tener el gusto de verlo [...]. Ahí le mando la carta que le tenía mi compadre Mariano y no se ofrece otra cosa sino es pedir a Dios me lo guarde por muchos años. Su muy afecta y querida esposa que sus manos besa y verlo desea.

María Celestina Rubio ${ }^{37}$.

37. AGN, Sección Colecciones, Fondo Bernardo J. Caicedo, caja 2, f. 27r. Esta carta fue publicada en: TOVAR PINZÓN, Hermes: "Cartas de amor y guerra". Anuario de Historia Social y de la Cultura, 12 (1984) 163-164. 
Uno de los aspectos más dramáticos de las guerras de Independencia fue el número de pérdidas de vida en el campo de batalla, cifra en la cual hay que reconocer que los hombres pusieron la mayor cuota de sacrificio ${ }^{38}$. Inmensa debió ser la zozobra de las madres, esposas, hermanas e hijas ante el destino de sus seres queridos en el campo de batalla en donde desde luego la muerte no era una posibilidad muy lejana. Esta fue la incertidumbre que exteriorizó desde la ciudad de Santa Fe la ciudadana Rosalía Gutiérrez al querer reconfirmar ante el gobierno republicano si su marido había sido asesinado, tal como lo insinuaban algunos rumores.

Santa Fe, 25 de octubre de 1815.

Noticiosa de tener V. conocimiento del ciudadano Luis Francisco Lamprea que militaba de oficial en los Ejércitos de Venezuela al mando del ciudadano general Simón Bolívar; he de merecer a V. se digne certificar, si puede, o darme una razón que acredite la suerte que dicho Lamprea, mi marido, corrió en la retirada que hicieron aquellas tropas; pues me han asegurado varios sujetos, de quienes por estar fuera de esta ciudad no puedo conseguir su testimonio, que los enemigos lo cogieron prisionero y lo pasaron por las armas: lo que necesito acreditar ante el Gobierno General.

Espero de V. este beneficio que gravaré en mi gratitud como su atenta estimadora.

Honorable ciudadana Rosalía Gutiérrez ${ }^{39}$.

En su escueta respuesta, el comandante Eladio Chirino confirmó que Lamprea había sido apresado por unos corsarios cuando navegaba hacia las costas de la Nueva Granada. Fue llevado luego a Coro o Puerto Cabello "[...] en donde fue sacrificado al furor de nuestros opresores, sellando de este modo con su sangre la libertad de nuestra Patria".

\section{6.- A modo de colofón}

En el marco de las guerras de Independencia de Colombia, entre todos los grupos sociales, las mujeres fueron sin duda uno de los más vulnerables por cuanto debieron padecer ya fuera directa o indirectamente los embates de la represión política y la represión económica en medio de este conflicto militar.

38. Existen algunos cálculos que bien vale la pena analizar para hacerse a una idea de la magnitud general de las bajas humanas. Según el historiador José María Samper, del conjunto total de la población neogranadina, más de 200.000 hombres murieron por los fragores de la guerra, es decir, aproximadamente un 15\%. SAMPER, José María: Ensayo sobre las Revoluciones políticas. Bogotá, Universidad Nacional de Colombia, 1969, p. 303.

39. AGN, Sección Archivo Anexo, Fondo Historia, tomo 18, f. 465r. 
Si bien las escasas cartas firmadas por las mujeres anónimas y de sectores populares no brindan una completa visión de la situación de este segmento de la población, las pocas que han podido hallarse en los repositorios documentales representan una ventana a través de la cual es posible asomarse a su complejo mundo y a su percepción sobre la crítica coyuntura bélica.

Las 15 cartas aquí transcritas ofrecen pistas valiosas sobre sus facetas como madres, esposas, hijas y compañeras de lucha, además de su actitud solidaria y su importancia como sostén de la familia en momentos cruciales de escasez. Pueda ser que no alcanzaran a descollar como protagonistas políticas de primera línea pero en sus espacios locales mostraron una participación activa que antes era propia del género masculino. En otras ocasiones, se constituyeron en voces de protesta y de resistencia ante los excesos y arbitrariedades. Estos escritos permiten ver además algunos rasgos de su postura política y los traumatismos que implicaban los cambios de gobierno y de marco jurídico.

Pero, principalmente, el mayor valor histórico que revelan estos documentos epistolares es que, aún en medio de las restricciones y las dificultades, algunas mujeres supieron aprovechar estos espacios de comunicación para exigir ante las autoridades especial consideración y mejores condiciones de vida no solo para ellas mismas sino para su núcleo afectivo y familiar. Para estos efectos, acudieron a los procedimientos legales y a las instituciones legítimamente constituidas. Gracias a sus oportunos reclamos pudieron enviarse mensajes claros a los ostentadores del poder sobre la necesidad de contemplar algunos límites y concesiones humanitarias bajo el fragor de la tensión política y militar. En estas reclamaciones, ellas solían sacar a relucir sus convicciones políticas y los servicios ofrecidos como pruebas de fidelidad.

El proceso de Independencia que abarcó más de una década no significó cambios drásticos e inmediatos en los derechos y las condiciones de las mujeres. Los discursos de igualdad y libertad propagados por la Ilustración y años más tarde por los gestores del movimiento emancipatorio no se vieron reflejados en beneficio de las mujeres ${ }^{40} \mathrm{y}$ habrían de pasar muchas décadas más para vislumbrar cambios concretos. Faltarían también muchos años para equipararse en derechos como ciudadanas. Esto revela a todas luces el problemático proceso de construcción de la modernidad en tiempos republicanos.

A fin de cuentas, las mujeres habían contribuido de distintas formas a la causa de la Independencia pero no contaron con espacios propicios de organización para exigir mejoras en sus condiciones sociales ni para reclamar sus derechos conforme a los cambios legales y políticos prometidos por los líderes de la revolución ${ }^{41}$. En

40. BERMÚDEZ, Suzy: Hijas, esposas y amantes. Género, clase, etnia y edad en las historia de América Latina. Bogotá, Ediciones Uniandes, 1992, p. 112.

41. CHERPAK, Evelyn: "Las mujeres en la Independencia. Sus acciones y sus contribuciones". 
los años posteriores a la guerra, una vez superada la efervescencia política y militar, retornarían a sus roles tradicionales aunque nuevamente tendrían que afrontar con estoicismo los embates de las guerras civiles que azotaron a Colombia a lo largo de los siglos posteriores ${ }^{42}$.

\section{8.-Referencias bibliográficas}

Acotaciones Bolivarianas. Decretos marginales del Libertador (1813-1830) (1960). Caracas, Fundación John Boulton.

Archivo Central del Cauca (ACC). Popayán-Colombia. Sala Independencia.

Archivo General de la Nación (AGN). Bogotá-Colombia. Fondos: Bernardo J. Caicedo, Embargos Historia, Secretaría de Guerra y Marina, tomo 1, f. 516r-v.

BERMÚDEZ, Suzy: Hijas, esposas y amantes. Género, clase, etnia y edad en la historia de América Latina. Bogotá, Ediciones Uniandes, 1992.

BERMÚDEZ, Suzy: "El "bello sexo" y la familia durante el siglo XIX en Colombia". Historia Crítica, 8 (1993) 34-51.

BUSHNELL, David: El Régimen de Santander en la Gran Colombia. Bogotá, El Áncora Editores, 1985.

CHERPAK, Evelyn: "Las mujeres en la Independencia. Sus acciones y sus contribuciones". En: VELÁSQUEZ TORO, Magdalena: Las mujeres en la historia de Colombia. Bogotá, Editorial Norma, 1995, tomo I, pp. 83-116.

CORTÁZAR, Roberto (Comp.): Cartas y Mensajes del General Francisco de Paula Santander. Bogotá, Academia Colombiana de Historia, 1956, vol. 2.

Decreto sobre asignaciones de sueldo a los servidores de la Patria: Bogotá, Imprenta Nacional, 1905. FERNÁNDEZ GARCÍA, Elena: Mujeres en la guerra de la independencia. Madrid, Silex, 2010.

GARCÍA LÓPEZ, Ana Belén: "La participación de las mujeres en la independencia hispanoamericana a través de los medios de comunicación". Historia y Comunicación Social, 16 (2011) 33-49.

GONZÁLEZ ERASO, Judith Colombia: "Representaciones de las mujeres en la Independencia desde la historiografía colombiana". Historelo. Revista de Historia Regional y Local, 3-5 (2011) 169-190.

GUHA, Ranajit: "Prefacio a los estudios subalternos". En: RODRÍGUEZ FREIRE, Raúl (Comp.): Estudios Subalternos: una cartografia a (des)tiempo, Popayán, Editorial Universidad del Cauca, 2013, pp. 73-74.

GUZMÁN PÉREZ, Moisés (Ed.): Mujeres y revolución en la independencia hispanoamericana. Morelia, Instituto de Investigaciones Históricas de la Universidad Michoacana de San Nicolás de Hidalgo, 2013.

HERRERA, Martha Cecilia y PERTUZ BEDOYA, Carol: "Narrativas femeninas del conflicto armado y la violencia política en Colombia: contar para rehacerse". Revista de Estudios Sociales, 53 (2015) 150-162.

LUX MARTELO, Martha Elisa: "Las mujeres en la Independencia en la Nueva Granada: acciones y

En: VELÁSQUEZ TORO, Magdalena: Las mujeres en la historia de Colombia. Bogotá, Editorial Norma, 1995, tomo I, pp. 84, 115.

42. Véase por ejemplo, HERRERA, Martha Cecilia y PERTUZ BEDOYA, Carol: "Narrativas femeninas del conflicto armado y la violencia política en Colombia: contar para rehacerse". Revista de Estudios Sociales, 53 (2015) 150-162. 
contribuciones". En: Historia que no cesa. La Independencia de Colombia, 1780-1830. Bogotá, Universidad del Rosario, 2010.

MARTÍNEZ MARTIN, Abel Fernando y OTÁLORA CASCANTE, Andrés Ricardo: "De Boyacá en los campos. La vida cotidiana a través de las condiciones de salud en los ejércitos del Rey y Libertador de Nueva Granada en 1819". En: GUERRERO BARÓN, Javier y WIESNER, Luis (comp.): Memoria, Historia y Nación. Bogotá, UPTC, 2010, pp. 243-275.

MESTRE SÁNCHEZ, Antonio: "La carta, fuente de conocimiento histórico". Revista de Historia Moderna, 18 (2000) 13-26.

MONSALVE, José Dolores: Las mujeres en la Independencia. Bogotá, Academia Colombiana de Historia, 2010.

PITA PICO, Roger: "De niñas escolares a madres y esposas: restricciones a la educación femenina en Colombia durante la temprana vida republicana, 1820-1828". Revista Interdisciplinaria de Estudios de Género, 3-5 (2017) 35.

QUINTERO MONTIEL, Inés: "Bolívar: las mujeres, la política y la gloria". Revista Credencial Historia, 274 (2010) 2-6.

RAMÍREZ, María Himelda: "Las mujeres en la Independencia de la Nueva Granada. Entre líneas". La Manzana de la Discordia 5-1 (2010) 45-54.

Recopilación de Leyes de la Nueva Granada: Bogotá, Imprenta de Zoilo Salazar, 1845, vol. I.

RESTREPO, José Manuel: Historia de la Revolución de la República de Colombia en la América Meridional. Medellín, Universidad de Antioquia-Universidad Nacional, 2009, 5. a ed., vol. I.

RODRÍGUEZ JIMÉNEZ, Pablo: Cartas de amor en tiempos de guerra. Bogotá, Universidad del Rosario, 2014, 2000.

SAMPER, José María: Ensayo sobre las Revoluciones políticas. Bogotá, Universidad Nacional de Colombia, 1969 .

TORRES RAMÍREZ, Isabel de y TORRES SALINAS, Daniel: Tesis doctorales sobre estudios de las mujeres en las universidades de España (1976-2005). Análisis bibliométrico y repertorio bibliográfico. Sevilla, Instituto Andaluz de la Mujer, 2007.

TOVAR PINZÓN, Hermes: "Guerras de opinión y represión en Colombia durante la Independencia (1810-1820)". Anuario Colombiano de Historia Social y de la Cultura, 11(1983) 220-221.

TOVAR PINZÓN, Hermes: "Cartas de amor y guerra”. Anuario de Historia Social y de la Cultura, 12 (1984) 155-169.

TOVAR PINZÓN, Hermes: "La lenta ruptura con el pasado colonial”. En: Historia económica de Colombia. Bogotá, Tercer Mundo Editores, 1994, 4. a edición.

VELÁSQUEZ TORO, Magdalena: "Condiciones jurídicas y sociales de la mujer". En: Nueva Historia de Colombia. Bogotá, Editorial Planeta, 1998, vol. IV. 